\title{
Erratum: Distinct spatiotemporal activity in principal neurons of the mouse olfactory bulb in anesthetized and awake states
}

\section{David G. Blauvelt ${ }^{1,2+}$, Tomokazu F. Sato ${ }^{1+}$, Martin Wienisch ${ }^{1,3}$, Thomas Knöpfel $^{4,5}$ and Venkatesh N. Murthy ${ }^{1,3 *}$}

${ }^{1}$ Department of Molecular and Cellular Biology, Harvard University, Cambridge, MA, USA

2 Harvard Medical School, Boston, MA, USA

${ }^{3}$ Center for Brain Science, Harvard University, Cambridge, MA, USA

${ }^{4}$ Division of Brain Sciences, Imperial College London, London, UK

${ }^{5}$ Laboratory for Neuronal Circuit Dynamics, RIKEN Brain Science Institute, Wako-shi, Japan

${ }^{*}$ Correspondence: vnmurthy@fas.harvard.edu

these authors have contributed equally to this work.

Edited by:

Aravinthan Samuel, Harvard University, USA

\section{A commentary on}

Distinct spatiotemporal activity in principal neurons of the mouse olfactory bulb in anesthetized and awake states by Blauvelt, D. G., Sato, T. F., Wienisch, M., and Murthy, V. N. (2013) Front. Neural Circuits 7:46. doi: 10.3389/fncir.2013.00046

Thomas Knöpfel, a key contributor to the work published recently in Frontiers in
Neural Circuits (Front. Neural Circuits 7:46. doi: 10.3389/fncir.2013.00046) was inadvertently omitted in the list of authors.

We apologize to the readers for the inconvenience caused by this omission.

Received: 05 June 2013; accepted: 06 June 2013; published online: 26 June 2013.
Citation: Blauvelt DG, Sato TF, Wienisch M, Knöpfel T and Murthy VN (2013) Erratum: Distinct spatiotemporal activity in principal neurons of the mouse olfactory bulb in anesthetized and awake states. Front. Neural Circuits 7:114. doi: 10.3389/fncir.2013.00114

Copyright @ 2013 Blauvelt, Sato, Wienisch, Knöpfel and Murthy. This is an open-access article distributed under the terms of the Creative Commons Attribution License, which permits use, distribution and reproduction in other forums, provided the original authors and source are credited and subject to any copyright notices concerning any third-party graphics etc. 